Tohoku J. Exp. Med., 1989, 157, 193-198

\title{
A Role of the Cancer Cell Membrane Fluidity in the Cancer Metastases: An ESR Study
}

\author{
Ichiro Nakazawa and Masamoto Iwaizumi* \\ The Third Department of Internal Medicine, Tohoku \\ University School of Medicine, and *the Chemical Research \\ Institute of Non-Aqueous Solutions, Tohoku University, \\ Sendai 980
}

\begin{abstract}
Nakazawa, I. and Imaizumi, M. A Role of the Cancer Cell Membrane Fluidity in the Cancer Metastases : An ESR Study. Tohoku J. Exp. Med., 1989, 157 (3), 193-198_ AH66F or Yoshida sarcoma (YS) cells were transplanted intraperitoneally into male Donryu rats. Cancer cells obtained from ascites were suspended in saline solution $\left(10^{7}\right.$ cells $\left./ \mathrm{ml}\right)$ after washing. Then, $0.1 \mathrm{ml}$ of each suspension obtained from both strains was injected into the tail vein of 5 rats, respectively. Each metastatic nodule, $1 \mathrm{~mm}$ or less in a diameter, thus obtained was then injected into the peritoneal cavity in which these metastatic cells come to free. After 10 days, cancer cells obtained from each ascites were suspended in phosphate buffered saline $\left(\mathrm{Ca}^{2+}\right.$ and $\mathrm{Mg}^{2+}$ free, $\mathrm{pH}$ 7.2) after washing. Each suspension $\left(10^{7}\right.$ cells $\left./ \mathrm{ml}\right)$ was violently vibrated with a definite amount of 5-doxyl stearic acid and spin labeling of cancer cell membrane was done. Furthermore, each specimen thus obtained was subjected to the electron spin resonance (ESR) measurement and the order parameter was determined from the spectra. In both YS and AH66F strains, the cell membrane fluidity of the metastatic cancer cell was increased at each temperature measured from $5^{\circ} \mathrm{C}$ through $35^{\circ} \mathrm{C}$. The results obtained here suggest that the change of the cell membrane fluidity of cancer cell is closely related with the cancer metastases. - cancer; cell membrane fluidity; metastases ; ESR ; phospholipid
\end{abstract}

Metastasis to other organ is one of the characteristics of cancer which makes it difficult to cure cancer patients. Therefore, it is desirable to clarify the mechanism of cancer metastasis in order to cure cancer patients. Fidler (1973a) reported that only $1 \%$ of B16 melanoma cells injected intravenously had survived to form actual pulmonary metastasis. Fidler (1973b) also succeeded in obtaining the highly metastatic strains of B16 melanoma by means of intravenous injection and tissue culture of the metastatic lesions. Bosmann et al. (1973) noticed the biochemical features of the most highly metastatic strain (F10), that is, the change in the electrophoretic mobility, surface glycoprotein, proteases and increasing degradative enzyme as compared with those of low metastatic B16 melanoma strain (F1). Miller et al. (1985) suggested that metastasis of human colonic cancer

Received October 12, 1988; revision accepted for publication February 2, 1989. 
would be owing to the specific tumor cell phenotypes. Nakazawa et al. (1978) studied lipid-chemical features of metastatic lesions of human cancer, and recognized a marked change in the phospholipid fatty acid composition of the metastatic lesions in the liver as compared with that of pimary lesions; the percentage of the fatty acids which promote membrane lipid fluidity was more increased in the metastatic lesions than in primary lesions. According to Horwitz et al. (1974), it had been suggested that polyunsaturated fatty acids of cellular phospholipid may increase the fluidity of cell membrane. Nakazawa and Goto (1981) reported that polyunsaturated fatty acids among the phospholipid fatty acid compostion increased in hepatic metastatic lesions of AH66F strain. Considering these findings it seems that the membrane lipid fluidity of the cancer cell is related to cancer metastases, since Singer and Nicolson (1972) pointed out that the phospholipid is one of the important components of the cell membrane. Griffith and Jost (1976) discussed the utility of lipid spin labels in biological membrane study of ESR. Nakazawa and Iwaizumi (1982) studied a relationship between cancer metastases and the fluidity of cancer cell membrane.

The present paper deals with the change of the cell membrane fluidity in metastaic cancer cells. The relation between the cell membrane fluidity and the cancer metastasis is also discussed again.

\section{Materials And Methods}

Animals. Donryu male rats weighing from 100 to $120 \mathrm{~g}$ were used in this work. They were given a pellet diet, NF (Oriental yeast Co., Ltd., Tokyo), and tap water freely.

Tumors. AH66F and Yoshida sarcoma (YS) cells which had been kept at the Department of Oncology, Research Institute for Tuberculosis and Cancer, Tohoku University, were transplanted into the peritoneal cavity of rats, respectively. Ascites of each tumor strain was collected about 7 days later, while not bloody, and centrifuged. Each sediment was then washed three times with $0.9 \% \mathrm{NaCl}$ solution. Ten million of cancer cells obtained from each strain were suspended in $1 \mathrm{ml}$ of $0.9 \% \mathrm{NaCl}$ solution and $0.1 \mathrm{ml}$ of the cell suspension was injected into the tail vein of 5 rats, respectively. The cell suspension was also transplanted intraperitoneally to 5 rats respectively as the control. The rats used for cancer metastatic formation were killed about 10 days later, and each metastatic nodule, sized $1 \mathrm{~mm}$ or less, was collected, respectively. Each metastatic nodule thus obtained was divided into two parts. One pat was provided for pathohistological examination and another was injected with a small amount of $0.9 \% \mathrm{NaCl}$ solution into the peritoneal cavity of normal rat to make free cancer cells, respectively. About 10 days later, each ascites was collected from each rat, while not bloody, and centrifuged at $4^{\circ} \mathrm{C}$. The cell was washed three times with Dulbecco's phosphate buffered saline (PBS) without $\mathrm{Ca}^{2+}$ and $\mathrm{Mg}^{2+}(\mathrm{pH}$ 7.2) by means of centrifugation at $4^{\circ} \mathrm{C}$.

The tumor cells were suspended in PBS mentioned above so that the suspension contained 10 million tumor cells per ml.

\section{Experimental procedures}

Labeling of cell membrane with probe. The spin label probe, 5-doxyl stearic acid, was purchased from Syva Associates, Palo Alto, CA, USA, and used without further purification. The probe was dissolved in ethanol at a concentration of $1 \mathrm{mg} / \mathrm{ml}$, and a definite amount of 5 -doxyl stearic acid in ethanol was dried under a stream of $\mathrm{N}_{2}$ onto the wall of small glass 
test tube $(10 \mathrm{ml})$. Then, $1 \mathrm{ml}$ of tumor cell suspension mentioned above was added to this film and vibrated violently by means of mixer (Model TM-105, Thermonics, Tokyo) for 1 min at room temperature. The test tubes were then kept at $0^{\circ} \mathrm{C}$.

ESR measurement. Each sample crammed with $0.5 \mathrm{ml}$ of the spin labeled tumor cell suspension in the capillary was subjected to ESR measurement. ESR spectra were taken on a X-band spectrometer (Varian E 112) with $100 \mathrm{kHz}$ modulation and phase sensitive detection at the temperatures from $5^{\circ} \mathrm{C}$ to $35^{\circ} \mathrm{C}$ at $5^{\circ} \mathrm{C}$ steps. The scan range was 100 gauss and scan time 8 min with time constant of $0.5 \mathrm{sec}$.

\section{Results}

Order parameter. The cell membrane fluidity was expressed as order parameter in this work. The derivation of order parameter from spin-label resonance spectra was discussed extensively by McConnel and McFarland (1972), and

TABLE 1. Fluidity of AH66F cancer cell membrane (order parameter)

\begin{tabular}{clc}
\hline $\begin{array}{c}\text { Temperature } \\
\left({ }^{\circ} \mathrm{C}\right)\end{array}$ & $\begin{array}{l}\text { Control } \\
(n=3)\end{array}$ & $\begin{array}{c}\text { Metastatic cells to liver } \\
(n=5)\end{array}$ \\
\hline 5 & $0.84 \pm 0.01^{*}$ & $0.80 \pm 0.03^{*}$ \\
10 & $0.80 \pm 0.01$ & $0.75 \pm 0.02$ \\
15 & $0.76 \pm 0.01$ & $0.71 \pm 0.02$ \\
20 & $0.72 \pm 0.01$ & $0.67 \pm 0.02$ \\
25 & $0.66 \pm 0.02$ & $0.62 \pm 0.01$ \\
30 & $0.61 \pm 0.02$ & $0.57 \pm 0.02$ \\
35 & $0.57 \pm 0.01$ & $0.52 \pm 0.01$ \\
\hline
\end{tabular}

* Mean \pm S.D.

The order parameter calculated from the spin label resonance spectra of AH66F.

$n$ represents the numbers of samples investigated.

TABLE 2. Fluidity of Yoshida sarcoma cell membrane (order parameter)

\begin{tabular}{ccc}
\hline $\begin{array}{c}\text { Temperature } \\
\left({ }^{\circ} \mathrm{C}\right)\end{array}$ & $\begin{array}{c}\text { Control } \\
(n=3)\end{array}$ & $\begin{array}{c}\text { Metastatic cells to liver } \\
(n=5)\end{array}$ \\
\hline 5 & $0.79 \pm 0.01^{*}$ & $0.74 \pm 0.01^{*}$ \\
10 & $0.77 \pm 0.01$ & $0.71 \pm 0.02$ \\
15 & $0.73 \pm 0.01$ & $0.66 \pm 0.01$ \\
20 & $0.68 \pm 0.01$ & $0.62 \pm 0.01$ \\
25 & $0.63 \pm 0.01$ & $0.60 \pm 0.01$ \\
30 & $0.59 \pm 0.01$ & $0.56 \pm 0.01$ \\
35 & $0.56 \pm 0.01$ & $0.53 \pm 0.01$ \\
\hline
\end{tabular}

*Mean \pm s.D.

The order parameter calculated from the spin label resonance spectra of YS.

$n$ represents the numbers of samples investigated. 
Gaffney (1976). The order parameter calculated according to their method from the spin-label resonance spectra of $\mathrm{AH} 66 \mathrm{~F}$ and $\mathrm{YS}$ in Table 1 and Table 2, respectively. In both strains, the value of order parameter of the hepatic metastatic cancer cells was significantly decreased statistically $(p<0.01)$ in each temperature measured, as compared with that of the control, respectively. The decrease of order parameter value represents the increase of the cell membrane fluidity.

\section{Discussion}

Cancer metastasis is one of behaviors of the living cancer cells. Furthermore, it seems that the cell membrane is not only a boundary membrane but the vividly functioning vital organ. A destruction of the cell membrane would make it difficult to obtain the information on the genuine cell membrane fluidity. Thus, it is necessary to study the cell membrane fluidity in a physiological condition near that, to clarify whether there is a correlation between cancer metastasis and the fluidity of the cancer cell membrane or not. The chemical composition and biophysical characters of the cell membrane should be controlled by DNA of the cell nucleus or some organelles. However, it is possible that the genuine cell membrane fluidity may be influenced by a manipulation to extract the cell membrane. Taking such a possibility into account, the cell membrane of intact cells was labeled with the probe in this work. Furthermore, the cells were treated in a sterilized condition as strict as possible. The cells collected from the peritoneal cavity were centrifuged in the sterilized test tube at $4^{\circ} \mathrm{C}$ and labeled with 5-doxyl stearic acid as described before. After that, they were kept at $0^{\circ} \mathrm{C}$ up to the ESR measurement. Scan time at each temperature was relatively short such as $8 \mathrm{~min}$. Therefore, less than $1 \mathrm{hr}$ was needed for the ESR measurement of each sample from $5^{\circ} \mathrm{C}$ to $35^{\circ} \mathrm{C}$. Thus, each sample was treated so rapidly that the probe was not incorporated into the cytosome of the cancer cells.

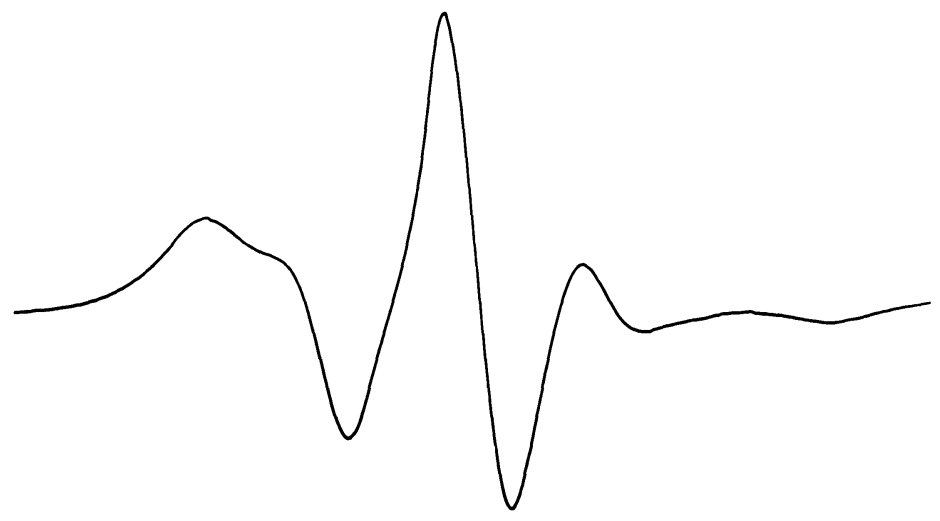

Fig. 1. EPR spectrum of AH66F measured at $25^{\circ} \mathrm{C}$. 
Adams et al. (1980) used excessive amounts of the fatty acid spin probe when MAT-A13762 tumor cells were labeled with the probe in the ESR measurement of the cell membrane fluidity. This seems that a part of spin probe would move into the cytosome. Furthermore the excessive probe may be harmful for the intact cell. Nakazawa and Iwaizumi (1982) reported that the probe used was localized at the cancer cell membrane when amounts of 5-doxyl stearic acid were between 0.01 and $0.05 \mathrm{mg}$ per $5 \times 10^{6}$ of cancer cells. In this work, 5 million of cancer cells were labeled with $0.02 \mathrm{mg}$ of 5-doxyl stearic acid. Thus, ESR spectra obtained here did not show any signal coming from two or more different sites of the cancer cells as shown in Fig. 1. Further, ESR spectra obtained in this study did not show any absorption which suggests a degradation of the probe in both strains (YS and $\mathrm{AH} 66 \mathrm{~F}$ ).

When the cell membrane fluidity is discussed, it would be necessary to give the evidence that the cell membrane used in experiments is intact. This would be rather difficult in the solid tumors than in the ascitic tumors, because the cancer cells metastasized into the other organ would be influenced in the metastatic lesions. Thus, it would be necessary to remove the influence to the metastatic cancer cells from the lesions metastasized. In this work, the hepatic metastatic nodule was transplanted intraperitoneally to make free metastatic cells naturally. In the solid tumors, however, it would be very difficult to isolate and prepare the metastatic cells without any change because it would be necessary to use some enzymes in order to make free metastatic cancer cells. It would be impossible to remove the effect of the lesions metastasized on the metastatic cancer cells. Therefore, it would be difficult to measure the genuine cell membrane fluidity of the metastatic cancer cells in the solid tumor system. The ascitic tumor strains, therefore, would be quite desirable to study the cell membrane fluidity of the metastatic cancer cell.

Sato (1967) reported the findings to suggest that the metastatic cancer cells would extravasate from the venule without a remarkable injury of the blood vessel in the mesenteric blood vessel system when tumor cells had been injected into the left carotid artery of the rats in both YS and AH66F strains, respectively. The decrease of the order parameter means the increase of the cell membrane fluidity. The results obtained in this work represent an increase of deformability (Sato and Suzuki 1976) of the metastatic cancer cells. Thus, it appears that the increased cell membrane fluidity is closely related to a process of cancer metastatic formation.

\section{Acknowledgments}

We wish to thank Emeritus Professor Haruo Sato and Professor Maroh Suzuki, Tohoku University, for the gift of YS and AH66F cells, and also for helpful advice and discussion. 


\section{References}

1) Adams, D.A., Smith, W.B., Powell, R.C. \& Caraway, K.I. (1980) Electron spin resonance and fluorescence observation on erythrocytes, erythrocyte membrane, 13762 Mat-A ascites adenocarcinoma cells and their membrane, effects of membrane perturbations. Membr. Biochem., 3, 207-228.

2) Bosmann, H.B., Bieber, G.F., Brown, A.E., Case, K.R., Gesten, D.M., Kimmerer, T.W. \& Lione, A (1973) Biochemical parameter correlated with tumor cell implantation. Nature (Lond.), 246, 487-489.

3) Fidler, I.J. (1973a) The relationship of embolic homogeneity, number, size, and viability to the incidence of experimental metastasis. Eur. J. Cancer, 9, 223-227.

4) Fidler, I.J. (1973b) Selection of successive tumor lines for metastasis. Nature New Biol., 242, 148-149.

5) Gaffney, B.J. (1976) Practical considerations for the calculation of order parameters for fatty acid or phospholipid spin labels in membranes. In: Spin Labeling, edited by L.J. Berliner, Academic Press, Inc., New York-San Francisco-London, pp. 453-523.

6) Griffith, O.H. \& Jost P.C. (1976) Lipid spin labels in biological membrane. In : Spin Labeling, edited by L.J. Berliner, Academic Press, Inc., New York-San Francisco-London, pp. 567-571.

7) Horwitz, A.F., Hatten, M.E. \& Burger, M.M. (1974) Membrane fatty acid replacement and their effect on growth and lectin-induced agglutinability. Proc. Natl. Acad. Sci. $U S A, 71,3115-3119$.

8) McConnel, H.M. \& McFarland, B.G. (1972) The flexibility gradient in biological membrane. Ann. N.Y. Acad. Sci., 195, 207-217.

9) Miller, W., David, O., Giacco, G., Guinee, V., Irimura, T., Nicolson, G. \& Cleary, K. (1985) Absence of a relationship of size of primary colon carcinoma with metastasis and survival. Clin. Exp. Metastasis, 3, 189-196.

10) Nakazawa, I. \& Goto, Y. (1981) A role of the cellular phospholipid in the metastasis into the liver. Cell. Mol. Biol., 27, 23-26.

11) Nakazawa, I. \& Iwaizumi, M. (1982) A correlation between cancer metastases and the fluidity of cancer cell membrane. Tohoku J. Exp. Med., 137, 325-328.

12) Nakazawa, I., Ohtsuki, M. \& Goto, Y. (1978) The lipid-chemical features of the metastatic tissues into the liver from the human gastric cancer, large intesinal cancer and malignant insulinoma. Tohoku J. Exp. Med., 126, 95-101.

13) Sato, H. (1967) Experimental pathology on ascites tumors, specially with reference to cancer metastasis. Trans. Soc. Pathol. Jpn., 56, 9-36.

14) Sato, H. \& Suzuki, M. (1976) Deformability and viability of tumor cells by trans capillary passage, with reference to organ affinity of metastasis in cancer. In: Fundamental Aspects of Metastasis, edited by L. Weis, North-Holland Publishing Co., Amsterdam-Oxford, pp. 311-317.

15) Singer, S.J. \& Nicolson, G.L. (1972) Fluid mosaic model of the structure of cell membrane. Science, 175, 720-731. 